
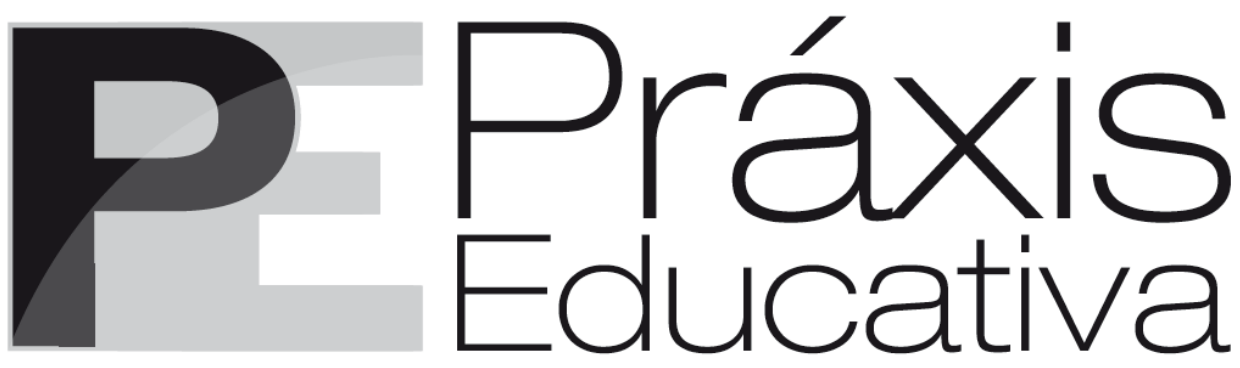

ISSN 1809-4309 (Versão online) DOI: 10.5212/PraxEduc.v.11i2.0013

\title{
KNECHTEL, Maria do Rosário. Metodologia da pesquisa em educação: uma abordagem teórico-prática dialogada. Curitiba: Intersaberes, 2014. 193 p.
}

Guilherme Leonardo Freitas Silva*

Maria do Rosário Knechtel é e Mestre em Ciências Sociais pela Universidade de São Paulo, Doutora em Sociologia da Educação pela Universidade Federal de Santa Maria (UFSM), Pós-Doutora em Educação Permanente e a Distância pela Universidad Nacional de Educacíon a Distancia (UNED), na Espanha, e Pós-Doutora em Sociologia e Educação Ambiental pela Universidade de Berlim, Karlsruhe, na Alemanha. Foi professora do Programa de Pós-Graduação em Educação da UFPR e UEPG e atualmente é professora e pesquisadora do Programa de PósGraduação em Meio Ambiente e Desenvolvimento da Universidade Federal do Paraná (UFPR) há 22 anos. Trabalha com temas relacionados à área da educação e da sociologia, à educação ambiental, à interdisciplinaridade, ao ensino superior, à educação permanente, à multi e interculturalidade, às políticas sociais, entre outros. Possui várias obras publicadas, entre elas, a da presente resenha.

A priori, o assunto sobre metodologia de pesquisa, como objeto de estudo, já tem sido debatido pelos pesquisadores do mundo inteiro, portanto poderíamos supor, em um primeiro momento, que o livro Metodologia da pesquisa em educação: uma abordagem teórico-prática dialogada viria apenas complementar uma base de conhecimento já existente sobre esse tema. Entretanto, o título da obra por si só nos chama a atenção por ser uma abordagem teórico-prática dialogada. Teórico-prática no sentido de delinear os pressupostos necessários para a construção do conhecimento por meio da reflexão crítica da teoria metodológica, trazendo exemplos, definições e esquemas, mapas conceituais muito bem elaborados e ilustrados, com a clareza e a experiência que a autora traz ao longo dos anos como professora e pesquisadora. A obra é dialogada no sentido dialético, em que a pesquisa e a aprendizagem, em um constante movimento, não se separam, mas se articulam ao longo do processo. Esse fato fundamental faz da leitura desse livro uma verdadeira obrigatoriedade para aqueles que se aventuram na pesquisa, sobretudo quando se deparam quanto à metodologia a ser adotada. Sua linguagem é clara e convidativa, pois ao longo do livro a autora dialoga com o leitor fazendo-o refletir sobre sua prática.

No capítulo 1, Teoria do conhecimento, pesquisa e ciência, a autora traz fundamentos, conceitos básicos, definições sobre o conhecimento e sobre a teoria do conhecimento, sobre a epistemologia e correntes filosóficas pertinentes ao tema. Ela ressalta a importância do ensino

\footnotetext{
* Egresso do PPGE/UEPG. Doutorando do Programa de Pós-Graduação em Meio Ambiente e Desenvolvimento - UFPR. E-mail: <jskalibur@yahoo.com.br>.
}

Práxis Educativa, Ponta Grossa, v. 11, n. 2, p. 531-534, maio/ago. 2016 Disponível em: <http://www.revistas2.uepg.br/index.php/praxiseducativa $>$ 
pela pesquisa e da pesquisa para o ensino, como eixos que se complementam, ou seja, ambos são conceitos diferentes, porém se relacionam, se complementam, como dizia Paulo Freire (2013, p. 30), “[...] não há ensino sem pesquisa e pesquisa sem ensino". Na parte sobre desenvolvimento do pensamento até chegar ao científico, é realizado um levantamento dos principais filósofos que contribuíram para a filosofia da educação - desde Aristóteles, passando por Francis Bacon, René Descartes, John Locke, George Berkeley, Auguste Comte, Émile Durkheim, Immanuel Kant, Edmund Husserl, Max Scheler, George W. F. Hegel, Karl Marx, Friedrich Engels, até Ludwig Feuerbach.

Uma das contribuições desse livro é a explicação do método dialético aplicado à educação, trazendo exemplos de trabalhos que foram orientados pela autora que utilizaram esse método. Além disso, a pesquisadora traz aspectos importantes sobre o paradigma de Marx relacionado a problemáticas socioeducacionais da atualidade. Por último, neste capítulo, a autora traz uma atividade final, por meio de mapas conceituais e uma revisão sobre a gênese do conhecimento científico, demonstrando a importância do pensamento e do método dialético para o estudo das contradições na realidade educacional.

No capítulo 2, O novo espírito científico, a autora demonstra uma preocupação inicial sobre a quantidade de informações advindas por meio da globalização e como isso se transforma em conhecimento. São oportunizadas reflexões sobre como surge o novo espírito científico e quais suas implicações no campo da educação. Nesse sentido, a autora traz a importância das interatividades e das interrelações que os sistemas complexos exigem, bem como a importante contribuição sobre abordagens da teoria da complexidade de Edgar Morin e como isso se aplica às condições e às pesquisas socioeducacionais.

No centro das considerações sobre a inter e a transdiciplinaridade, a autora apresenta uma experiência de pesquisa qualitativa e prática realizada com doutorandos do Programa de Pós-Graduação em Meio Ambiente e Desenvolvimento da Universidade Federal do Paraná (UFPR), por meio da análise de conteúdo dos discursos dos alunos da turma de 2008. Nesse exemplo, a autora relata as falas dos discentes (doutorandos) sobre os conceitos e as práticas de inter e transdiciplinaridade, demonstrando a importância da reflexão e da prática pedagógica interdisciplinar vivenciada. Esse trabalho foi apresentado em Seminário Internacional de Inter e Transdisciplinaridade em Barcelona, em 2010, com a presença de Morin, de La Torre e outros.

Por último, nesse capítulo, a autora apresenta os níveis de pesquisa em educação - desde o primeiro nível de interpretação produtiva, passando pela interpretação própria, pela reconstrução do conhecimento, pela construção própria, até chegar ao quinto nível da criação/descoberta. A pesquisadora demonstra a importância da pesquisa como papel mediador na formação dos professores pesquisadores. Novamente, ela levanta questões como forma de uma atividade final relacionando os problemas que os professores vivenciam na atualidade, além de trazer uma revisão do capítulo.

No capítulo 3, Pesquisa científica, a autora expõe um esquema introdutório à pesquisa e como se origina um estudo monográfico. Na sequência, são demonstrados os tipos de pesquisa com abordagens quantitativas e qualitativas. Com a colaboração de Júlio Gnap, estatístico e mestre em Sociologia pela UFPR, Knechtel apresenta, detalhadamente, como tratar de dados quantitativos, dados primários e secundários. Segue um exemplo de dados estatísticos, utilizando uma pesquisa realizada sobre os acidentes de trabalho ocorridos no emprego formal no Paraná em 2003. Isso dá ao leitor uma noção de como é possível utilizar esse método, por meio de técnicas como: experimentos de campo, pesquisa descritiva, pesquisa exploratória, acrescentando,

Práxis Educativa, Ponta Grossa, v. 11, n. 2, p. 531-534, maio/ago. 2016 Disponível em: <http://www.revistas2.uepg.br/index.php/praxiseducativa> 
KNECHTEL, Maria do Rosário. Metodologia da pesquisa em educação: uma abordagem...

ainda, um roteiro das etapas e passos para a realização de uma pesquisa quantitativa, desde a identificação do problema, definição dos objetivos, planejamento, coleta e processamento de dados, análise dos resultados até chegar à produção do relatório final. $\mathrm{O}$ mesmo acontece na explanação da pesquisa qualitativa.

Uma contribuição importante da obra é a maneira como a autora diferencia as pesquisas quantitativas das pesquisas qualitativas por meio de quadros explicativos, tornando a compreensão fácil para o leitor. Knechtel discute também a possibilidade da integração entre os dois tipos de pesquisa na área da educação, quando necessário o cruzamento de dados para sustentação da pesquisa.

Um ponto chave do livro é a elucidação dos paradigmas da pesquisa aplicados à educação, em que a autora apresenta abordagens filosóficas como o positivismo, pós-positivismo, teoria crítica, fenomenologia e dialética. Nesse sentido, é possível o leitor perceber as diferenças e as aproximações nas suas principais características, trazendo sempre um elo com a educação. Como atividade final desse capítulo, a autora propõe completar um quadro com as principais caraterísticas de cada paradigma de pesquisa, além de fazer a revisão do capítulo.

No quarto capítulo, Pesquisa: planejamento e execução, é apresentado um roteiro para elaboração de projeto de pesquisa qualitativa com os itens: tema, problema, justificativa, objetivos (geral e específicos), pressupostos teóricos, fundamentação, metodologia, considerações finais e referências. Mais uma vez são elucidados os tipos de pesquisa de acordo com seus objetivos: exploratória, descritiva, explicativa.

Com base nos procedimentos técnicos, a autora explica-os detalhadamente como: bibliográfica, documental, experimental, ex post facto, levantamento, estudo de campo, estudo de caso, pesquisa-ação e pesquisa participante. Na parte prática, a autora comenta como fazer pesquisa na área da educação, por meio do delineamento da pesquisa, revisão bibliográfica, coleta de dados, organização dos dados, análise e interpretação dos dados e redação final. Ela chama a atenção para o enfoque de pesquisa de campo na área da educação, dá exemplos e ideias de questões formuladas a partir da problematização da realidade.

No item procedimentos metodológicos da pesquisa, merece atenção especial a obtenção de dados na área da educação por meio de observações, de entrevistas, de questionários, exemplificando cada um deles. Também é revelado como é feito o tratamento dos dados, a análise e a interpretação, a análise de conteúdo, as conclusões e as discussões. Por último, nesse capítulo, a autora traz uma atividade que permite ao leitor analisar, bem como elaborar um trabalho na área de educação. Ao final do capítulo, Knechtel novamente apresenta uma revisão que permite ao leitor refletir sobre os procedimentos metodológicos abordados no livro.

Para concluir é a fase subtítulo final desse livro que permite relembrar que essa obra considerou duas dimensões: a pesquisa teórico-metodológica e a ênfase na abordagem dialógica como pressuposto do aprender a aprender. Além disso, a autora enfatiza o desejo de continuar pesquisando na área de educação sempre buscando uma reflexão crítica para a construção do conhecimento.

Essa obra é indicada para educadores formais, não formais, informais, para professores de diversos níveis de ensino, para estudantes na sua fase inicial de pesquisa como para estudos de Pós-Graduação. Enfim, o livro é para qualquer cidadão que se sinta preocupado não só com uma

Práxis Educativa, Ponta Grossa, v. 11, n. 2, p. 531-534, maio/ago. 2016 Disponível em: <http://www.revistas2.uepg.br/index.php/praxiseducativa> 
educação para além dos limites impostos metodologicamente, mas com uma educação dialogada e aberta.

\section{Referências}

FREIRE, P. Pedagogia da autonomia: saberes necessários à prática educativa. 45. ed. Rio de Janeiro: Paz e Terra, 2013. 